\title{
Chemical composition and antioxidant potential of Acacia leucophloea Roxb.
}

\author{
MuHAMMAD Zia-Ul-HaQ ${ }^{1}$, SANJA ĆAVAR ${ }^{2, *}$, Mughal QAYUM ${ }^{3}$, \\ INAMULLAH KHAN ${ }^{4}$, SHAKEEL AHMAD ${ }^{5}$ \\ ${ }^{1}$ Research Institute of Pharmaceutical Sciences, Department of Pharmacognosy, \\ University of Karachi, Karachi 75270, Pakistan \\ ${ }^{2}$ University of Sarajevo, Faculty of Science, Department of Chemistry, \\ 71000 Sarajevo, Bosnia and Herzegovina \\ ${ }^{3}$ Department of Pharmacy, Kohat University of Science and Technology, Kohat 2600, \\ Pakistan \\ ${ }^{4}$ Department of Pharmacy, University of Peshawar, Peshawar 25120, Pakistan \\ ${ }^{5}$ Department of Agronomy, Bahauddin Zakariya University, Multan 60800, Pakistan
}

\begin{abstract}
The aim of this study was to evaluate the compositional and nutritional potential of methanolic extracts of various parts of Acacia leucophloea Roxb. concerning the chemical composition and antioxidant potential of which limited information is available. Compositional studies indicated carbohydrates as major components in both seed and pods. Despite differences in mineral content among the leaves, pods and seeds, calcium was found in the highest amount and zinc in the lowest. The amino acid profile indicated aspartic acid as the major amino acid and proline as the minor. Among protein fractions, globulin was present in higher amounts than other fractions. Linoleic acid was the major fatty acid detected in the oil from both pods and seeds, while $\gamma$-tocopherol was the major component of the tocopherol observed from same oil. Moreover, significant antioxidant potential was observed from the extracts of all three parts investigated. The results obtained in this study clearly indicate that A. leucophloea has a sufficient potential for use as a natural antioxidant agent. Further phytochemical studies will be performed for specification of the biologically active principles.
\end{abstract}

Key words: Acacia leucophloea, mineral content, amino acids, fatty acids, tocopherols, sterols, antioxidant activity
Abbreviations:
AOAC - Association of Official Analytical Chemists; BHA - butylated hydroxy anisole; BHT - butylated hydroxy toluene; FRAP - ferric reducing antioxidant power; ROS - re- active oxygen species; TAC - total antioxidant capacity; TEAC - Trolox equivalent anti- oxidant capacity; TRAP - radical-trapping antioxidant parameter.

* Corresponding author, e-mail: sanja_cavar@yahoo.com

Copyright ${ }^{\circledR} 2013$ by Acta Botanica Croatica, the Faculty of Science, University of Zagreb. All rights reserved. 


\section{Introduction}

The Leguminosae form the third largest plant family in the world, comprising about 650 genera and 18000 species. The subfamily Mimosoideae, with 3000 species in 50-60 genera, is distributed worldwide and is abundant in tropical, subtropical and warm-temperate areas (PolHill and Raven 1981). Acacia is the most significant genus of the subfamily Mimosoideae. It is estimated that there are roughly 1380 species of Acacia worldwide, about two-third of them native to Australia and rest spread around tropical and subtropical regions of the world (SAINI et al. 2008). Acacia species although distributed throughout Pakistan, are mostly found in Sindh and Punjab Province. In Pakistan 34 species of Acacia are reported, most of them growing wild (NASIR and Ali 1974, AKHTAR 1992). Acacia contains organic compounds, many of which are psychoactive in humans. The alkaloids found include dimethyltryptamine (DMT), 5-methoxydimethyltryptamine (5-MeO-DMT) and $N$-methyltryptamine (NMT). Similarly, many cyanogenic glycosides have also been isolated from this species (DAVID et al. 1987). Acacia is effective when used as a coating on pills to make the bitterness easier to swallow or digest. It is important to the food industry as a flavor fixative and emulsifier. This plant has been used in traditional medicine to treat high cholesterol, diabetes, cancer, gingivitis, mouth sores, pharyngitis, and indigestion in children. Acacia leucophloea Roxb. is a moderate-sized dry-season fodder and pasture tree, found in various parts of Pakistan and is known for its nutritional and medicinal potential. Its germinated seeds are eaten after cooking. Its leaves, tender shoots, and pods are readily consumed by goats, sheep and cattle. Accacia leucophloea bark has a foul smell and its fibers are used to make fish nets and rough rope. The bark yields water soluble gum of fair quality (Troup 1983) which is demulcent and used as emulsifying agent. Bark is used to purify liquor and yields a reddish-brown stain which is used for the preparation of dyes. Moreover, the bark is used against snake bites (SELVANAYAGAM et al. 1995, WALTER et al. 2000). The seed sprouts are consumed as a vegetable in some parts of Indonesia. The species is treasured as firewood and is appropriate for charcoal production. Acacia leucophloea is a good reforestation species for poor soils in low rainfall areas (ORWA et al. 2009). Traditionally, parts of this plant are used against diarrhoea, cancer, inflammation, ophthalmia, hemorrhoid, leprosy, bleeding piles, and leucoderma problems. Its young leaves and pods are used as an astringent. The leaves are believed to possess hypotensive, CNS-depressent, antisyphilitic and antimicrobial principles, while the gum possesses demulscent properties (KHARE 2007).

The human body has numerous mechanisms to shield biomolecules against reactive oxygen species (ROS) induced damage. However, the instinctive protection may not be adequate for rigorous or continuous oxidative stress. Hence, certain amounts of exogenous antioxidants are frequently required to maintain sufficient antioxidants level to balance the ROS-pressure in the human body. Synthetic antioxidants such as butylated hydroxanisole (BHA) and butylated hydroxytoluene (BHT) although very effective, are not without side-effects and should be replaced with natural antioxidants. Various natural antioxidants like flavonoids, phenols, tannins, and terpenoids, reported from crude herbal extracts, may lessen ROS-pressure due to their inherent ability to scavenge reactive oxygen/nitrogen radical species (ROS/RNS), chelating metal catalysts, activating antioxidant enzymes, and inhibiting oxidases (GRACE 2005). In this context, as part of our continuous studies on 
exploring the hidden potential of indigenous flora of Pakistan (ZIA-UL-HAQ et al. 2007; 2008a, b; 2009; 2010; 2011), this investigation focuses mainly on exploring A. leucophloea as a source of food, feed, and antioxidant source to provide baseline data for future commercial exploitation and for overcoming malnutrition-associated problems.

\section{Materials and methods}

\section{Plant material}

Acacia leucophloea (seeds, leaves, flower and pods) plant material was collected from Khanewal, a district of Multan, Punjab, Pakistan in June 2008, and authenticated by Saima Shehzadi, a taxonomist in charge of the herbarium at the institute of Pure and Applied Biology, Bahauddin Zakariya University, Multan and a voucher specimen was deposited for future identification.

\section{Extraction}

The plant material (Acacia leucophloea seeds, leaves, flower and pods) was air-dried in shade and crushed to coarse powder separately with help of pestle and mortar. Plant material (0.5 kg each) was macerated with an aqueous methanolic mixture $(80: 20 ; \mathrm{v} / \mathrm{v}$, $1 \mathrm{~L})$, at room temperature for fifteen days with occasional shaking. The process was repeated three times with the same quantity of solvent mixture. The extracts so obtained were combined, filtered through filter paper under vacuum and concentrated under reduced pressure in a rotary evaporator (model Q-344B - Quimis, Brazil) using a warm water bath (model Q-214M2 - Quimis, Brazil) to obtain a thick gummy mass, which was further dried in a desiccator and stored in an air-tight vial until tests for antioxidant activities were performed.

\section{Proximate analysis}

Moisture, lipids, ash, protein, and carbohydrates of seeds were determined according to AOAC (1990).

\section{Mineral content}

The samples (100 mg) after acid digestion (a nitric/perchloric acid (2:1) mixture) were used for elemental analysis. Sodium and potassium were estimated by flame photometer (Flame Photometer Model-EEL). An atomic absorption spectrometer (Perkin-Elmer Model 5000) was used to measure calcium, manganese, magnesium, zinc, copper, and iron, while phosphorus was determined by the phosphovanado-molybdate method (ZIA-UL-HAQ et al. 2007). The samples were quantified against standard solutions of known concentration that were analyzed concurrently.

\section{Estimation of seed protein fractions}

Cold trichloroacetic acid 20\% was used for extracted protein (RAJARAM and JANARDHANAN 1990) purification by precipitation. The seed protein fractions, albumins and 
globulins were extracted (MURRAY 1979). The remaining pellet was treated with $80 \%$ ethanol (1:5 w/v) overnight and centrifuged at 20,000 x $g$ for $20 \mathrm{~min}$, and the supernatant containing prolamine was air-dried and dissolved in $0.1 \mathrm{~N} \mathrm{NaOH}$. The final remaining pellet was extracted with $0.4 \mathrm{~N} \mathrm{NaOH}(1: 10 \mathrm{w} / \mathrm{v})$ overnight and centrifuged at 20,000 $\mathrm{x} g$ for 20 min and the supernatant thus obtained was the glutelin proteins. The fractions obtained were determined for protein content (LowRY et al. 1951).

\section{Amino acid content}

Hydrochloric acid (6M) was used to hydrolyze samples in an evacuated test tube for $24 \mathrm{~h}$ at $105^{\circ} \mathrm{C}$. The dried residue was dissolved in citrate buffer $(\mathrm{pH}$ 2.2) after flash evaporation. Aliquots were analyzed in an automatic amino acid analyzer (Hitachi Perkin-Elmer Model KLA 3B), using the buffer system described earlier. Methionine and cysteine were analyzed separately after performic acid treatment and subsequent hydrolysis with $\mathrm{HCl}$ (KHALILet al. 1990). Tryptophan was determined after alkali $(\mathrm{NaOH})$ hydrolysis by the colorimetric method (FREIDMAN and FINELY 1971).

\section{Fatty acid composition}

Fatty acid composition of extracted oils was determined following the ISO draft standard ISO/FIDS 5509 (1997). One drop of the oil was dissolved in $1 \mathrm{~mL}$ of $n$-heptane, 50 $\mu \mathrm{L} 2 \mathrm{M}$ sodium methanolate in methanol were added, and the closed tube was agitated vigorously for $1 \mathrm{~min}$. After addition of $100 \mu \mathrm{L}$ of water, the tube was centrifuged at $4500 \mathrm{x} \mathrm{g}$ for $10 \mathrm{~min}$ and the lower aqueous phase was removed. After that, $50 \mu \mathrm{L}$ of $1 \mathrm{M} \mathrm{HCl}$ were added to the $n$-heptane phase, the two phases were briefly mixed and the lower aqueous phase was rejected. About $20 \mathrm{mg}$ of sodium hydrogen sulphate were added, and after centrifugation at $4500 \mathrm{~g}$ for $10 \mathrm{~min}$ the top $n$-heptane phase was transferred into a vial and injected in a Varian 5890 gas chromatograph with a capillary column, CP-Sil88 (100 m long, $0.25 \mathrm{~mm}$ ID, film thickness $0.2 \mu \mathrm{m})$. The temperature programme was: from $155^{\circ} \mathrm{C}$ heated to $220^{\circ} \mathrm{C}\left(1.5^{\circ} \mathrm{C} \mathrm{m^{-1 }}\right), 10$ min isotherm; injector $250{ }^{\circ} \mathrm{C}$, detector $250{ }^{\circ} \mathrm{C}$; carrier gas $1.07 \mathrm{~mL} \mathrm{~min}^{-} \mathrm{H}_{2}$; split ratio 1:50; detector gas $30 \mathrm{~mL} \mathrm{~min}^{-1} \mathrm{H}_{2} ; 300 \mathrm{~mL}$ per min air and $30 \mathrm{~mL}$ per min $\mathrm{N}_{2}$; manual injection volume less than $1 \mu \mathrm{L}$. The integration software computed the peak areas and percentages of fatty acid methyl esters (FAME) were obtained as weight percent by direct internal normalization.

\section{Tocopherol content}

For determination of tocopherols a solution of $250 \mathrm{mg}$ of oil from the samples studied in $25 \mathrm{~mL} n$-heptane was directly used for HPLC. The HPLC analysis was conducted using a Merck-Hitachi low-pressure gradient system, fitted with an L-6000 pump, a Merck-Hitachi F-1000 Fluorescence Spectrophotometer (detector wavelengths for excitation $295 \mathrm{~nm}$, for emission $330 \mathrm{~nm}$ ) and a D-2500 integration system; $20 \mu \mathrm{L}$ of the samples were injected by a Merck 655-A40 Autosampler onto a Diol phase HPLC column $25 \mathrm{~cm}$ x $4.6 \mathrm{~mm}$ ID (Merck, Darmstadt, Germany) using a flow rate of $1.3 \mathrm{~mL} \mathrm{~min}^{-1}$. The mobile phase used was $n$-heptane / tert-butyl methyl ether $(99+1, \mathrm{v} / \mathrm{v})$. Calibration was done by external standards with $\alpha$-, $\beta$-, $\gamma$ - and $\delta$-tocopherol (Calbiochem, Bad Soden, Germany) (BALz et al. 1992). 


\section{Sterol composition}

The determination of sterols was made following the official method of the Association of Official Analytical Chemists (AOAC 1990). Seed oil was saponified, while unsaponifiable matter was extracted with diethyl ether, and solvent was removed under vacuum. Then sterols were separated from other unsaponifiables by thin layer chromatography (TLC Silica gel 60 F254; Merck, Darmstadt, Germany) using a solvent system of hexane:diethyl ether $(70: 30 \mathrm{v} / \mathrm{v})$. The spots were visualized with 2,7 -dichlorofluorescein $(0.2 \%$ in alcohol). The sterols band was identified under UV light by comparing the Rf value with that of authentic cholesterol (Sigma Aldrich Co., St. Louis, MO, USA). The recovered sterol from silica gel was converted to trimethylsilyl ether derivatives using a mixture of hexamethyldisilane-trimethylchlorosilane (99:1, v/v). Analysis of transformed sterols was carried out on a Perkin Elmer gas chromatograph model 8700, equipped with methyl phenyl polysiloxane coated capillary column OV-17 (30 $\mathrm{m} \times 0.25 \mathrm{~mm}, 0.20 \mu \mathrm{m}$ film thickness) and a Flame Ionization Detector (FID). The column was isothermally operated at a temperature of $255^{\circ} \mathrm{C}$. Injector and FID temperatures were set at 275 and $290{ }^{\circ} \mathrm{C}$, respectively. Extra pure $\mathrm{N}_{2}$ at a flow rate of $3 \mathrm{~mL} \mathrm{~min}^{-1}$ was used as a carrier gas. The internal standard used was 5 - $\alpha$-cholestane. Identification and quantification of the unknown sterol components were performed using a pure sterol standard mixture.

\section{Total antioxidant capacity determination}

Plant extracts were analyzed for their antioxidant capacity by three different TAC assays: 1) Trolox equivalent antioxidant capacity (TEAC) assay, 2) ferric reducing antioxidant power (FRAP) assay and 3) total radical-trapping antioxidant parameter (TRAP) assay.

\section{Trolox equivalent antioxidant capacity (TEAC) assay}

A stable stock solution of ABTS.+ was produced by reacting a $7 \mathrm{mmol} \mathrm{L}-1$ aqueous solution of ABTS with $2.45 \mathrm{mmol} \mathrm{L}^{-1}$ potassium persulfate (final concentration) and allowing the mixture to stand in the dark at room temperature for $12-16 \mathrm{~h}$ before use. At the beginning of the analysis day, an ABTS-+ working solution was obtained by the dilution in ethanol of the stock solution to an absorbance of $0.70 \pm 0.02 \mathrm{AU}$ at $734 \mathrm{~nm}$, verified by a Hewlett-Packard 8453 Diode Array spectrophotometer (HP, Waldbronn, Germany), and used as mobile phase in a flow-injection system. Results were expressed as micromoles of Trolox per g of plant extract (PELLEGRINI et al. 2003).

\section{Ferric reducing antioxidant power (FRAP) assay}

The principle of this method is based on the reduction of a ferric-tripyridyltriazine complex to its ferrous coloured form in the presence of antioxidants. Briefly, the FRAP reagent contained $5 \mathrm{~mL}$ of a $\left(10 \mathrm{mmol} \mathrm{L}^{-1}\right)$ TPTZ (2,4,6-tripyridyl-s-triazine) solution in $40 \mathrm{mmol}$ $\mathrm{L}^{-1} \mathrm{HCl}$ plus $5 \mathrm{~mL}$ of $\mathrm{FeCl}_{3}\left(20 \mathrm{mmol} \mathrm{L}^{-1}\right)$ and $50 \mathrm{~mL}$ of acetate buffer $\left(0.3 \mathrm{~mol} \mathrm{~L}^{-1}, \mathrm{pH}=3.6\right)$ and was prepared freshly and warmed at $37^{\circ} \mathrm{C}$. Aliquots of $100 \mu \mathrm{L}$ sample were mixed with $3 \mathrm{~mL}$ FRAP reagent and the absorbance of reaction mixture at $593 \mathrm{~nm}$ was measured spectrophotometrically after incubation at $37{ }^{\circ} \mathrm{C}$ for $10 \mathrm{~min}$. For construction of calibration curve five concentrations of FeSO x $7 \mathrm{H}_{2} \mathrm{O}\left(1000,750,500,250,125 \mu \mathrm{mol} \mathrm{L}^{-1}\right)$ were used and the absorbencies were measured as sample solution. The values were expressed as the 
concentration of antioxidants having a ferric reducing ability equivalent to that of $1 \mathrm{mmol}$

$\mathrm{L}^{-1} \mathrm{FeSO}_{4}$. Results were expressed as micromoles of $\mathrm{Fe}^{2+}$ equivalents per $\mathrm{g}$ of plant extract (BENZIE and STRAIN 1999).

\section{Total radical-trapping antioxidant parameter (TRAP) assay}

This method is based on the protection provided by antioxidants on the fluorescence decay of R-phycoerythrin (lag-phase) during a controlled peroxidation reaction. Briefly, 120 $\mu \mathrm{L}$ of diluted sample were added to $2.4 \mathrm{~mL}$ of phosphate buffer ( $\mathrm{pH} 7.4$ ), $375 \mu \mathrm{L}$ of bidistilled water, $30 \mu \mathrm{L}$ of diluted R-PE and $75 \mu \mathrm{L}$ of ABAP; the reaction kinetics at $38{ }^{\circ} \mathrm{C}$ were recorded for $45 \mathrm{~min}$ (or more, if necessary) by a LS-55 luminescence spectrometer (Perkin Elmer, Wellesley, MA). TRAP values were calculated from the length of the lag-phase due to the sample compared with that of Trolox and expressed as $S$ micromoles of Trolox per $g$ of plant extract (GHISELLI et al. 1995).

\section{Statistical analysis}

Analyses were performed in triplicate. Data analysis was carried out using the analysis of variance and LSD test using the »MSTATC« statistical computer package.

\section{Results and discussion}

The wide variation in geological and climatic conditions and agronomic practices of $\mathrm{Pa}-$ kistan offers the broadest array of flora harboured by the forests, deserts, mountains and rivers. This rich floral biodiversity of Pakistan constitutes an impressive pool for žnatural pharmacy' from which the indigenous communities select ingredients to prepare herbal recipes (phytomedicines) for the treatment, management and control of their various ailments. Much of the potential of these botanicals is however still untapped. In current research, a less explored medicinal tree found in Pakistan has been investigated for various nutritional parameters.

Proximate composition is an important indicator and the first step during nutritional evaluation of fruits and seeds of plants and crops; it also dictates further studies of any component that seems more interesting. Proximate composition indicated the presence of higher amounts of proteins $(25.81 \pm 0.93 \%$ and $13.81 \pm 0.93 \%)$ and carbohydrate $(52.30 \pm 1.16 \%$ and $46.75 \pm 0.89 \%$ ) in seed than pod, respectively (Tab. 1). Similarly, a higher content of fibres indicates its potential use in bakery and pastry products. Our results are in agreement

Tab. 1. Proximate chemical composition of Acacia leucophloea Roxb.

\begin{tabular}{lrr}
\hline \multicolumn{1}{c}{ Component } & \multicolumn{1}{c}{ Seeds $(\%)$} & \multicolumn{1}{c}{ Pods $(\%)$} \\
\hline Crude protein & $25.81 \pm 0.93$ & $13.81 \pm 0.93$ \\
Total lipids & $5.03 \pm 0.07$ & $4.75 \pm 0.09$ \\
Total carbohydrates & $52.30 \pm 1.16$ & $46.75 \pm 0.89$ \\
Crude fiber & $6.70 \pm 0.38$ & $19.11 \pm 0.44$ \\
Moisture & $5.61 \pm 0.23$ & $9.57 \pm 0.79$ \\
Ash & $4.55 \pm 0.56$ & $6.01 \pm 0.19$ \\
\hline
\end{tabular}


with those reported earlier for the seeds (VIJAYAKUMARI et al. 1994). To the best of our knowledge, no previous study exists on pod proximate composition. Ash content was higher in pod $(6.01 \pm 0.19 \%$ and $4.55 \pm 0.56 \%)$ indicating a higher mineral content in pods, while lipid content was lower in pod $(5.03 \pm 0.07 \%$ and $4.75 \pm 0.09 \%)$ than in seeds (Tab. 1). Pods usually have lower levels of protein and lipids, and greater fiber content than found in seeds. Usually the proximate composition of plants and crops seeds varies depending on the cultivars, climatological conditions, maturity and collection time of seed, water and fertilizer application as well as acceptability, selectivity and intake of nutrients by plants and crops (ZIA-Ul-HaQ et al. 2011).

Mineral contents indicated potassium was present in the highest concentration, 11.47 and $13.09 \mathrm{~g} \mathrm{~kg}^{-1}$, in seed and pod, respectively (Fig. 1), while leaves had a higher concentration of calcium $\left(17.32 \mathrm{~g} \mathrm{~kg}^{-1}\right)$. Sufficient amounts of calcium, magnesium and phosphorus were present in all three parts analyzed. Potassium was observed to be the main element in pods. Since leaves and pods of the Acacia species investigated are is a rich source of minerals, they may be added as mineral supplement in ruminant diets as high mineral contents are considered essential for various physiological functions of browsing animals. High levels of

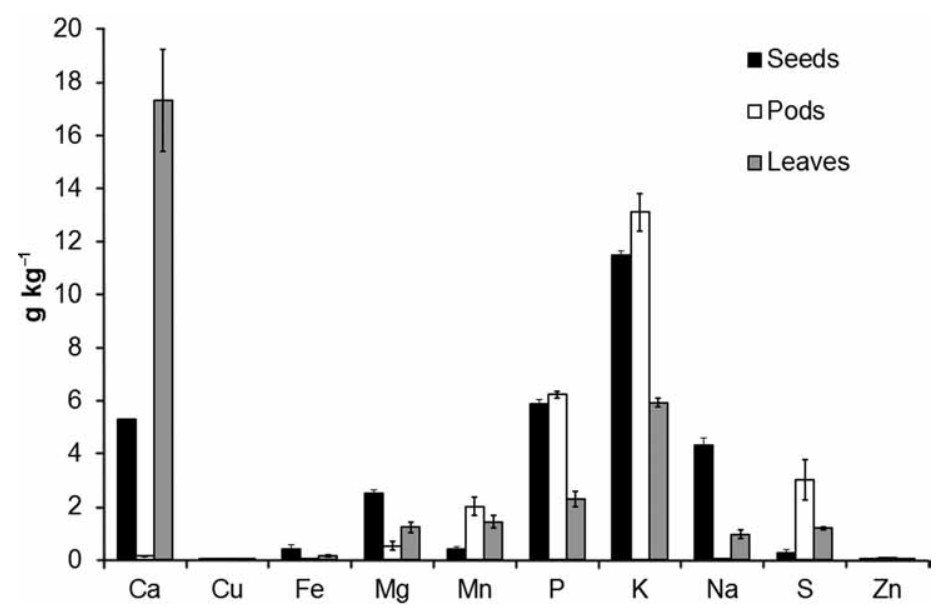

Fig. 1. Mineral contents of Acacia leucophloea Roxb.

calcium are required during growth, gravidity and lactation of animals. Results are comparable with another closely related species, A. nilotica seed (SIDDHURAJU et al. 1996), and leaves (RUBANZA et al. 2007, KumAR et al. 2010). The differences, however, may be due to the different unit for the expression of mineral content. Mineral content found in all parts are promising, as all these parts are eaten by animals, providing their mineral requirements. To the best of our knowledge, no previous studies of the micronutrients of pods of $A$. leucophloea exist.

Presented results for seed protein fractions indicated the highest amounts of globulins $13.01 \pm 1.27 \%$ and $6.12 \pm 0.25 \%$, while prolamines, $1.21 \pm 0.54 \%$ and $1.09 \pm 0.46 \%$, were present in the lowest amounts in both seed and pods, respectively (Tab. 2). Mostly seed proteins of legumes are higher in globulin and lower in prolamines. Lesser content of albumins 
Tab. 2. Protein fractions of seed and pods of Acacia leucophloea Roxb.

\begin{tabular}{crc}
\hline Protein fractions & Seeds $(\%)$ & Pods $(\%)$ \\
\hline Albumins & $9.67 \pm 0.39$ & $5.18 \pm 0.89$ \\
Globulins & $13.01 \pm 1.27$ & $6.12 \pm 0.25$ \\
Prolamines & $1.21 \pm 0.54$ & $1.09 \pm 0.46$ \\
Glutelins & $2.32 \pm 1.08$ & $2.03 \pm 0.77$ \\
\hline
\end{tabular}

(sulphur containing) in pods is responsible for the lesser content of sulphur-containing amino acids. The presented results are comparable to those reported earlier for the seeds (VIJAYAKUMARI et al. 1994). However, no previous studies of the pods exist.

Amino acid content (Table 3) indicated that glutamic acid (17.29 $\pm 0.75 \%$ and $15.46 \pm$ $0.89 \%)$ and aspartic acid (13.07 $\pm 0.69 \%$ and $10.21 \pm 0.42 \%)$ are present in the highest concentrations, while methionine $(0.63 \pm 0.84 \%$ and $0.17 \pm 0.23 \%)$, and cysteine $(1.21 \pm$ $0.72 \%$ and $1.03 \pm 0.19 \%$ ) are present in the lowest concentrations. Our results are comparable to those reported earlier for seeds (VIJAYAKUMARI et al. 1994). However, like other parameters, no previous studies pods exist of.

Tab. 3. Amino acid composition of Acacia leucophloea Roxb.

\begin{tabular}{lrr}
\hline Amino acid & Seeds $(\%)$ & \multicolumn{1}{c}{ Pods $(\%)$} \\
\hline Alanine & $6.86 \pm 0.33$ & $8.77 \pm 0.21$ \\
Arginine & $6.35 \pm 0.19$ & $5.16 \pm 0.62$ \\
Aspartic acid & $13.07 \pm 0.69$ & $10.21 \pm 0.42$ \\
Cysteine & $1.21 \pm 0.72$ & $1.03 \pm 0.19$ \\
Glutamic acid & $17.29 \pm 0.75$ & $15.46 \pm 0.89$ \\
Glycine & $8.02 \pm 0.05$ & $6.91 \pm 0.34$ \\
Histidine & $4.36 \pm 0.52$ & $3.41 \pm 0.62$ \\
Isoleucine & $3.89 \pm 0.41$ & $4.13 \pm 0.49$ \\
Leucine & $8.01 \pm 0.29$ & $9.17 \pm 0.32$ \\
Lysine & $6.08 \pm 0.11$ & $8.03 \pm 0.92$ \\
Methionine & $0.63 \pm 0.84$ & $0.17 \pm 0.23$ \\
Phenylaniline & $4.62 \pm 0.71$ & $4.62 \pm 0.71$ \\
Proline & $5.24 \pm 0.64$ & $2.01 \pm 0.44$ \\
Serine & $4.37 \pm 0.73$ & $6.39 \pm 0.23$ \\
Threonine & $3.86 \pm 0.48$ & $5.96 \pm 0.48$ \\
Tryptophan & $0.32 \pm 0.08$ & $0.91 \pm 0.22$ \\
Tyrosine & $2.03 \pm 0.55$ & $2.03 \pm 0.14$ \\
Valine & $4.73 \pm 0.07$ & $5.63 \pm 0.11$ \\
\hline
\end{tabular}

Fatty acid composition (Fig. 2) indicated the presence of linoleic acid in the highest proportion $(49.60 \pm 1.01 \%$ and $35.92 \pm 1.01 \%)$, while sufficient amounts of oleic acid $(22.67 \pm$ $0.89 \%$ and $24.12 \pm 0.44 \%$ ) and palmitic acid $(17.80 \pm 0.17 \%$ and $26.09 \pm 0.75 \%)$ are also present in seeds and pods. The presented results are close to those reported earlier (VIJAYA- 


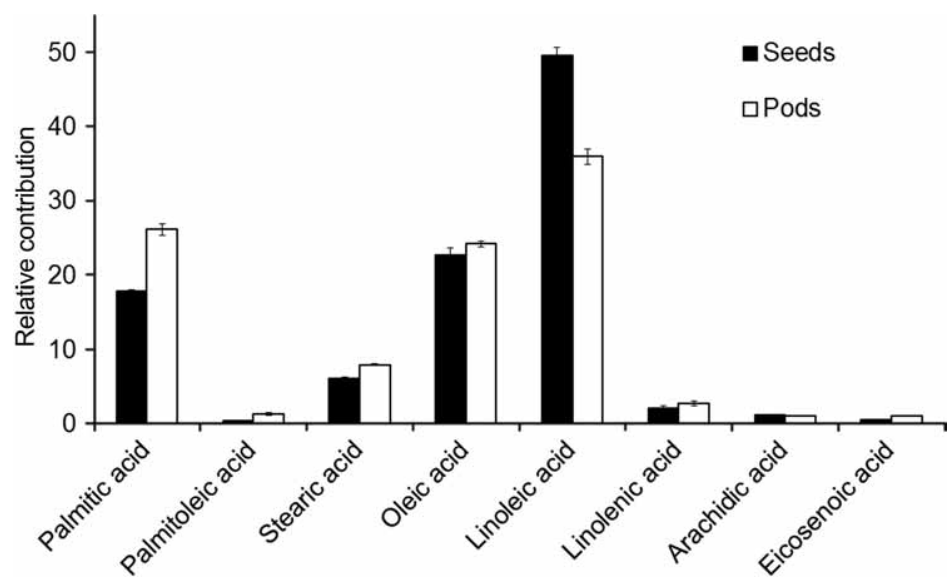

Fig. 2. Fatty acid profile of Acacia leucophloea Roxb.

KUMARI et al. 1994; ZIA-UL-HAQ et al. 2007, 2008). Linoleic acid, have been reported to prevent cardiovascular disorders such as coronary heart disease, atherosclerosis, as well as high blood pressure. Oils containing more unsaturated fatty acids are believed to reduce cholesterol-related heart diseases.

$\gamma$-Tocopherol was found in the highest amount (169.81 $\pm 1.44 \mathrm{mg}$ per $100 \mathrm{~g})$ in the oils of this plant species while $\beta$-tocopherol was found in the lowest amount $(1.04 \pm 0.76 \mathrm{mg}$ per 100 g) (Fig. 3). Since it is known from the literature that tocopherols significantly increase the stability of vegetable oils, we suppose that acacia oil will also have a long shelf life time because of its high tocopherol contents. No previous study reports tocopherol contents of Acacia species. High amounts of tocopherols can be interesting for the production of naturally occurring tocopherols for the stabilization of fats and oils against oxidative deterioration and for applications in dietary, pharmaceutical, or biomedical products. Sterol profile of seed oil indicated that $\beta$-sitosterol was the major sterol $\left(73.07 \pm 0.90 \mathrm{mg}\right.$ per $100 \mathrm{~g}$ ), while $\Delta^{7}$ -

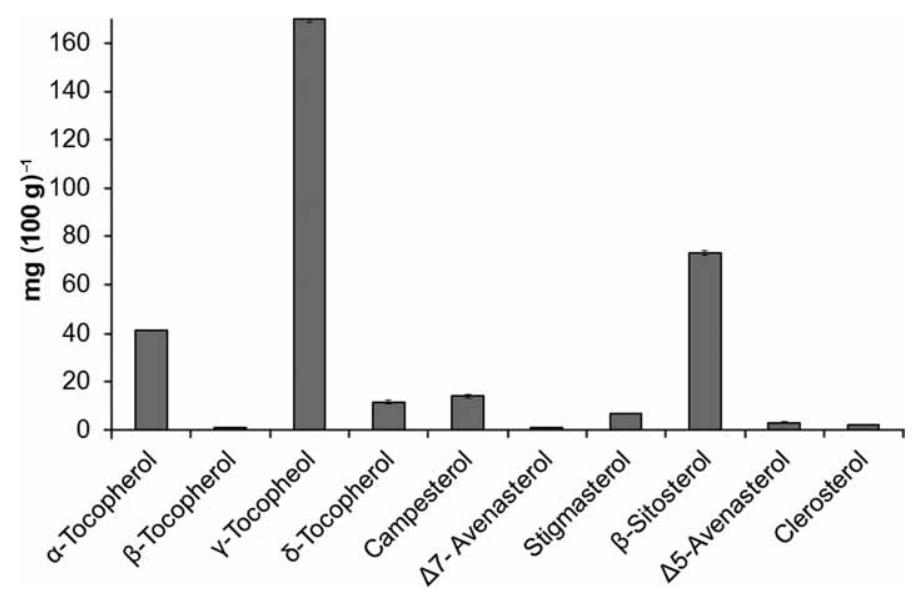

Fig. 3. Tocopherol and sterol profile of oils from seeds of Acacia leucophloea Roxb. 
avenasterol was present in the lowest amount $(1.04 \pm 0.76 \mathrm{mg}$ per $100 \mathrm{~g})$. Like other parameters, this is the first report on the sterol content of A. leucophloea. However, the values are close to those reported earlier for other Acacia species (FALADE et al. 2008).

The results from the antioxidant assays (Tab. 4) showed that all examined extracts might to a certain extent act as radical scavengers. The distinct scavenging activities of different extracts can be due to the diverse chemical nature of various phytochemicals. Our results vary to a large extent from those reported previously (SHANG-TZEN et al. 2001). This may be due to the differences in assay performed and cultivar used. All parts of A. leucophloea may be good candidatse for further development as an antioxidant remedy. In-depth investigations are necessary, covering at least two or three years' data to permit insight into yearly variations of seeds grown under defined conditions (agronomic practices, pesticide use, fertilization, irrigation and climatic data).

Tab. 4. In vitro antioxidant activity by various assays Acacia leucophloea Roxb.

\begin{tabular}{lccc}
\hline Sample & TEAC $\left(\mu \mathrm{mol} \mathrm{g}^{-1}\right)$ & FRAP $\left(\mu \mathrm{mol} \mathrm{g}^{-1}\right)$ & TRAP $\left(\mu \mathrm{mol} \mathrm{g}^{-1}\right)$ \\
\hline Leaves & $543.03 \pm 1.17$ & $233.17 \pm 1.24$ & $68.39 \pm 1.12$ \\
Pods & $683.23 \pm 1.42$ & $254.42 \pm 1.86$ & $76.02 \pm 1.37$ \\
Seeds & $529.66 \pm 1.55$ & $178.14 \pm 1.14$ & $49.14 \pm 1.34$ \\
\hline
\end{tabular}

\section{Conclusion}

In conclusion, the results obtained in this study clearly indicate that A. leucophloea has a sufficient potential for use as a source for a herbal recipe for the treatment, management and control of various ailments, as well as a natural antioxidant agent. Further phytochemical studies will be performed for specification of the biologically active principles.

\section{References}

AKHTAR, S., 1992: Chemical and nutritional evaluation of genus acacia of the family Leguminosae of pakistan. PhD Thesis, University of Punjab Lahore, Pakistan.

AOAC, 1990: Official methods of analysis of the Association of Official Analytical Chemists. Association of Official Analytical Chemists, Washington, DC.

Balz, M., Shulte, E., Their, H. P., 1992: Trennung von Tocopherolen und Tocotrienolen durch HPLC. Lipid/ Fett 94, 209-213.

Benzie, I. F. F., Strain, J. J., 1999: Ferric reducing/antioxidant power assay: direct measure of total antioxidant activity of biological fluids and modified version for simultaneous measurement of total antioxidant power and ascorbic acid concentration. Methods in Enzymology 299, 15-27.

DAVID, S., SeIgler, J., Ebinger, E., 1987: Cyanogenic glycosides in ant-acacias of Mexico and central America. The Southwestern Naturalist 32, 499-503.

Falade, O. S., Adekunle, A. S., Aderogba, M. A., Atanda, S. O., Harwood, C., ADEWUSI, S. R., 2008: Physicochemical properties, total phenol and tocopherol of some Acacia seed oils. Journal of Science of Food and Agriculture 88, 263-268. 
FreidmAn, M., Finely, J. W., 1971: Methods of tryptophan analysis. Journal of Agriculture Food Chemistry 19, 626-631.

Ghiselli, A., Serafini, M., Maiani, G., Azzini, E., Ferro-Luzzi, A., 1995: A fluorescence-based method for measuring total plasma antioxidant capability. Free Radical Biology and Medicine 18, 29-36.

GraCE, S. C., 2005: Phenolics as antioxidants. In SMIRnOFF, N. (ed.), Antioxidants and reactive oxygen species in plants, 141-168. Blackwell Publishing, Oxford.

Khalil, I. A., Durani, F. R.,1990: Haulm and Hull of peas as a protein source in animal feed. Sarhad Journal of Agriculture 6, 219-225.

KHARE, C. P., 2007: Indian medicinal plants, an illustrated dictionary. Springer, Stuttgart.

Kumar, J. I. N., Kumar, R. N., Bhoi, R. K., Patel, K., 2010: Seasonal changes of bioelements in litter and their potential return to green leaves in five species of tropical dry deciduous forest, western India. Journal of Forestry Research 21, 33-38.

Lowry, O. H., Rosenbrough, N. J., FARr, A. L., Randall, R. J., 1951: Protein measurement with Folin phenol reagent. Journal of Biological Chemistry 1993, 265-275.

NAsir, E., Ali, S. I., 1974: Flora of west Pakistan. University of Karachi, Feroz Sons Press, Karachi.

MurRAY, D. R., 1979: The seed proteins of kowhai, Sophora microphylla AIT. Z. Pflazenphysiology 93, 423-428.

Orwa, C., Mutua, A., Kindt, R., Jamnadass, R., Simons, A., 2009: Agroforestree. A tree reference and selection guide, version 4.0. Retrieved July 02, 2012, from http://www. worldagroforestry.org/treedb2/AFTPDFS/Acacia_leucophloea.pdf

Pellegrini, N., Serafini, M., Colombi, B., del Rio, D., Salvatore, S., Bianchi, M., BRIGHENTI, F. 2003: Total antioxidant capacity of plant foods, beverages and oils consumed in Italy assessed by three different in vitro assays. Journal of Nutrition 133 , 2812-2819.

RAJARAM, N., JANARDHANAN, K., 1990: Chemical composition and nutritional evaluation of certain under-exploited Vigna spp. Food Science and Nutrition 42, 213-221.

Rubanza, C. D. K., Shem, M. N., BaKengesa, S. S., Ichinohe, T., Fujihara, T., 2007: The content of protein, fiber and minerals of leaves of selected Acacia species indigenous to north-western Tanzania. Archive in Animal Nutrition 61, 151-156.

Polhill, R. M., Raven, P. H., 1981: Advances in legume systematics, Royal Botanic Gardens, Kew and Ministry of Agriculture, Fisheries and Food, London.

SAini, M. L., SAini, R., Roy, S., Kumar, A., 2008: Comparative pharmacognostical and antimicrobial studies of acacia species (Mimosaceae). Journal of Medicinal Plants Research 12, 378-386.

Selvanayagam, Z. E., Gnavavendhan, S. G., Balakrishna, K., Bhima, R. R., Usman, S. A., 1995: Survey of medicinal plants with anti snake venom activity in Chengalpattu district, Tamilnadu, India. Fitoterapia 66, 488-494.

Shang-Tzen, C., Jyh-Horng, W., Sheng-YAng, W., Pei-Ling, K., Ning-Sun, Y., Lie-Fen, S., 2001: Antioxidant activity of extracts from Acacia confusa bark and heartwood. Journal of Agriculture and Food Chemistry 49, 3420-3424. 
Siddhuraju, P., Vijayakumari, K., Janardbanan, K., 1996: Chemical composition and nutritional evaluation of an underexploited legume, Acacia nilotica (L.).Del. Food Chemistry 57, 385-391.

Troup, R. S., 1983: Troup's silviculture of Indian trees, 4. Leguminosae. Forest Research Institute and Colleges, Dehra Dun, India.

VijayAKumari, K., Siddhuraju, P., JanARdhanan, K., 1994: Nutritional assessment and chemical composition of the lesser known tree legume, Acacia leucophloea (Roxb.) Willd. Food Chemistry 50, 285-288.

Walter, B. M., Nascimento, M. C., Pereira, B. M., Pereira, N. A., 2000: Plant natural products active against snake bite, the molecular approach. Phytochemistry 55, 627642.

Zia-Ul-Haq, M., Ahmad, S. Shad, M. A., Iqbal, S., Qayum, M., Ahmad, A., Luthria, D. L,. Amarowicz, R., 2011: Compositional studies of some of lentil cultivars commonly consumed in Pakistan. Pakistan Journal of Botany 43, 1563-1567.

Zia-Ul-Haq, M., Ahmad, S., Ahmad, M., Iqbal, S., Khawar, K. M., 2009: Effects of cultivar and row spacing on tocopherol and sterol composition of chickpea (Cicer arietinum L.) seed oil. Tarim Bilimeri Dergisi 15, 25-30.

Zia-Ul-Haq, M., Ahmad, S., Chiavaro, E., Mehjabeen M., Ahmed, S., 2010: Studies of oil from cowpea (Vigna unguiculata (L.) Walp.) cultivars commonly grown in Pakistan. Pakistan Journal of Botany 42, 214-220.

Zia-Ul-HaQ, M., IQbal, S., Ahmad, M., 2008a: Characteristics of oil from seeds of 4 mungbean (Vigna radiate L. Wilczek) cultivars grown in Pakistan. Journal of American Oil Society 85, 851-856.

Zia-Ul-Haq, M., Iqbal, S., Ahmad, S., Bhanger, M. I., WiczKowski, W., Amarowicz, R., 2008b: Antioxidant Potential of Desi Chickpea varieties commonly consumed in Pakistan. Journal of Food Lipids 15, 326-342.

Zia-Ul-Haq, M., Iqbal, S., Ahmad, S., Imran, M., Niaz, A., Bhanger, M. I., 2007: Nutritional and compositional study of Desi Chickpea (Cicer arietinum L.) cultivars grown in Punjab, Pakistan. Food Chemistry 105, 1357-1363. 